\title{
Comments on Monetary Policy at the Effective Lower Bound
}

\begin{abstract}
Constraints on the setting of short-term interest rates due to the effective lower bound are likely to bind more often in the future than in the past if the neutral real rate of interest remains in the neighborhood of 1 percent. This paper argues that the Federal Open Market Committee should commit to pursuing a "lower-for-longer" or "makeup" strategy for setting short-term rates when the zero bound binds. This strategy is consistent with the goal of targeting 2 percent inflation, on average, over the business cycle. A "lower-for-longer" approach would improve economic performance during zero-lower-bound episodes and avoid an erosion of inflation expectations.
\end{abstract}

$\mathrm{n}$ the coming years, the Federal Reserve faces the significant issue of how to provide the accommodation the economy needs to recover from future downturns. This issue is important because constraints on the setting of short-term rates due to the zero (or effective) lower bound on interest rates may well bind more often in the future than they have in the past. Michael Kiley and John Roberts (2017) recently showed that the zero bound would constrain monetary policy 40 percent of the time if the neutral nominal short-term rate is 3 percent and the Federal Open Market Committee (FOMC) conducts policy by following a standard monetary policy rule, such as the Taylor rule. The consequence would be poor economic performance with significant shortfalls in output and employment during zero-lower-bound episodes. In addition, with inflation averaging about 2 percent when the zero lower bound does not bind and often declining to below 2 percent when it does, inflation, on average, will fall short of the

Conflict of Interest Disclosure: The author did not receive any financial support from any firm or person for this paper or from any firm or person with a financial or political interest in this paper. She is currently not an officer, director, or board member of any organization with an interest in this paper. 
FOMC's 2 percent target. Such a persistent inflation shortfall could erode inflation expectations over time, compounding the zero-lower-bound constraint by lowering the normal nominal short-term rate consistent with any given neutral real rate.

The increased relevance of the zero lower bound reflects the fact that the neutral real rate of interest $\left(r^{*}\right)$ looks to have declined considerably in recent decades while inflation expectations have become well anchored around the FOMC's 2 percent target. There is a good deal of uncertainty about both the current magnitude and future evolution of $r^{*}$. Empirical estimates are sensitive to methodology. However, updated estimates from Thomas Laubach and John Williams's (2003) model place $r^{*}$ at currently just a bit under 1 percent. And FOMC participants estimate that the longerrun normal real federal funds rate is in this same range, with the median estimate of $r^{*}$ between 0.75 and 1.00 percent. The causes of the decline in $r^{*}$, which is also evident in other advanced economies, are uncertain, but appear to be structural and persistent. They include low productivity growth; declining trend labor force growth, reflecting aging societies; and an increased preference for safe assets.

To improve economic performance, the FOMC could consider a number of approaches. Some involve the deployment of unconventional tools, such as longer-term asset purchases, interventions to directly target longerterm yields (similar to the Bank of Japan's yield curve control approach); and negative nominal interest rates. Other approaches, such as raising the inflation target or adopting price or nominal GDP targeting, entail a change in policy goals. I have argued that asset purchases have worked and thus should remain in the Fed's tool kit. But this tool will not likely fully alleviate the zero-lower-bound problem. The other approaches that I have mentioned deserve study and debate, but I see considerable disadvantages with each of them. Their shortcomings were recently summarized by my colleague, Ben Bernanke (2017). I agree with his assessments and, given the space constraints of this paper, I instead focus on an approach I consider promising - one that is evolutionary, practical, and has the potential to significantly mitigate the adverse effects of the zero lower bound.

I believe the FOMC should seriously consider pursuing a "lower-forlonger," or "makeup," strategy for setting short-term rates when the zero lower bound binds and, ideally, articulate its intention to do so before the next zero-lower-bound episode. The phrase "lower for longer" is due to David Reifschneider and John Williams (2000), who suggested that the Fed, during a zero-lower-bound period, could keep track of the cumulative deviations of short-term rates from the recommendations of a simple rule 
(the Taylor rule) and then "work off" or "make up" these accommodation shortfalls over time by holding short-term rates lower for a longer time than the rule would recommend. Under this strategy, the average level of short rates over a period of, say, 10 years from the onset of a zero-lower-bound episode would be essentially unaffected by the zero-lower-bound constraint. If this strategy is understood and credible, it should cause long-term rates to decline when the zero lower bound begins to bind by about as much as would occur in the absence of any effective lower bound at all-that is, if the FOMC could set negative rates. Under the empirically reasonable assumption that what matters for aggregate spending is the entire expected path of short-term rates rather than just the current level, this strategy enables the Fed to provide substantial additional accommodation during zero-lower-bound episodes. The strategy also potentially supports aggregate demand by raising inflation expectations, thereby lowering real long-term rates relative to a Taylor rule-type baseline.

A key characteristic of lower-for-longer strategies is that they do not treat "bygones" as "bygones." In determining the timing of exit from the zero lower bound and the subsequent path of short-term rates, the FOMC must consider not only the current state of the economy-the levels of the output gap and inflation, as in the Taylor rule-but also a measure of past performance shortfalls during the zero-lower-bound period-either cumulative shortfalls in monetary accommodation or cumulative shortfalls in output and inflation relative to the FOMC's targets. In effect, the FOMC would augment the usual factors incorporated in standard rules with an adjustment reflecting the severity of the zero-lower-bound episode. One technique is to characterize the appropriate policy path by reference to a "shadow" rate of interest that cumulates accommodation shortfalls. Reifschneider and Williams (2000) and Kiley and Roberts (2017) have proposed policies along these lines. An alternative approach is to characterize the same shortfalls in metrics relating to economic outcomes. Bernanke recently proposed such an approach-"flexible temporary price level targeting." He suggests that the FOMC hold rates at the zero lower bound at least until the cumulative shortfall in inflation from a 2 percent trend during the zero-lower-bound period has been eliminated and until unemployment has also at least declined to its natural rate.

This lower-for-longer strategy is attractive for several reasons. First, it is evolutionary; it builds on the existing flexible inflation targeting framework with an unchanged 2 percent longer-run inflation objective. This framework is well understood and, in my view, has contributed considerably to the attainment of good macroeconomic performance in the United 
States. It has helped to anchor inflation expectations, which, in turn, has enabled the FOMC to all but ignore the inflationary implications of supply shocks-and to instead focus on stabilizing employment.

This approach would build on the forward guidance the FOMC offered after 2008, which was explicitly intended to bring down long-term rates. The FOMC adopted forward guidance pertaining to the path of short-term rates that increasingly shifted market expectations, in effect promising to hold them below rule-based recommendations for a substantial time into the recovery-the essence of the lower-for-longer approach. A full evaluation of the impact of this guidance is difficult, because it evolved over time, along with the market's understanding of the economic impact of the financial crisis, and was complemented by asset purchases. However, long rates fell 20 basis points when the FOMC announced in August 2011 that the funds rate would stay at zero at least through mid-2013. The yield curve moved down further as the date moved out and the FOMC, in 2012, adopted threshold-based guidance, pledging that it would not raise rates at least until unemployment declined below 6.5 percent if inflation was projected to run no higher than 2.5 percent. Also, professional forecasters significantly reduced their estimates of the unemployment rate that would prevail at the time of liftoff.

The FOMC subsequently provided guidance that further pushed out the likely date of liftoff, and it only began to raise short-term rates when the unemployment rate had declined to 5 percent, close to estimates of the longer-run normal rate of unemployment at the time. The FOMC's guidance commanded broad FOMC support and, in my view, a significant degree of commitment, although it did not meet the "Odyssean" standard. When the FOMC finally began to raise rates, it promised a "gradual" approach, holding the funds rate below Taylor-type rule recommendations, even with an adjustment for the estimated decline in $r^{*}$. In addition, the FOMC has more recently emphasized the symmetry of the 2 percent inflation objective, and recent projections envision an overshoot of the 2 percent target in 2020, although there has been no statement or indication that the FOMC intends or considers it appropriate to "make up" for the cumulative inflation shortfall. This general approach, including the adoption of explicit quantitative thresholds, was consistent with the spirit of lower-for-longer-type recommendations and provides a basis on which the FOMC could build.

For the lower-for-longer approach to work well in future zero-lowerbound episodes, the FOMC needs to make a credible statement endorsing such an approach, ideally before the next economic downturn. This could take the form of a revision of the FOMC's "Statement on Longer-Run Goals 
and Monetary Policy Strategy," or it could be couched as an addendum to this statement on "Committee Guidelines for Implementing Policy at the Zero Lower Bound." Such a statement should enunciate the approach; show that the FOMC understands and embraces its implications; and, to the extent possible, provide quantitative guidance about how the policy would be implemented. It would be important for the FOMC to emphasize to both the public and Congress that the lower-for-longer approach is consistent with the Federal Reserve's congressional dual mandate to pursue maximum employment and price stability.

The FOMC could explicitly endorse the approach that it will set shortterm rates lower for longer than would be called for by standard monetary policy rules when the zero lower bound binds. It could elaborate that in setting the policy path, it will take previous performance shortfalls into account. It could establish quantitative thresholds consistent with such a strategy. For example, it could indicate that, after a period of very weak economic activity and inflation below 2 percent, it would generally be appropriate to wait to raise rates at least until the unemployment rate has declined to estimates of its normal longer-run level and inflation has stably returned to 2 percent-typical requirements of the policy path under any implementation.

As Bernanke has suggested, the FOMC could go further, stating that a condition for raising rates is that cumulative shortfalls of inflation from 2 percent have been erased. It could emphasize that once the Fed begins to raise short-term rates, it expects to close the gap with normal rule-based recommendations only gradually, in order to compensate for the shortfall in accommodation provided during the period when policy rates were constrained and as an appropriate risk management strategy. It could also emphasize that it anticipates that the additional stimulus provided by this approach will result in a period of exceptionally low unemployment, and that inflation would likely overshoot the FOMC's symmetric 2 percent target for a time, emphasizing the desirability of compensating for a previous shortfall to avoid an erosion of inflation expectations. It could articulate that the FOMC's objective is to achieve inflation near 2 percent, on average, over the business cycle.

The lower-for-longer strategy entails some costs and risks that need to be assessed and managed. By keeping interest rates unusually low after the zero lower bound no longer binds, the lower-for-longer approach promises, in effect, to allow the economy to boom after a zero-lower-bound episode. Unemployment will typically undershoot the longer-run normal rate of unemployment - a development that, in and of itself, I consider beneficial. 
Inflation would also typically rise above the 2 percent inflation target for some period, albeit not on a permanent basis. One could argue, in this regard, that such an overshoot helps to keep inflation at 2 percent "on average" (as is explicit in Bernanke's proposal), and that it is desirable because it makes the long-run level of prices more predictable—although this line of reasoning raises the question of whether the FOMC should more generally pursue a flexible price-level targeting strategy—an approach that would involve a very substantial alteration in the FOMC's policy framework. A prolonged period of inflation above 2 percent could potentially unanchor inflation expectations; and prolonged boom conditions could undermine financial stability. These concerns may militate in favor of some "tempering" in the application of the lower-for-longer approach. They raise the issue, as well, of whether the FOMC could credibly commit to such a plan. Market participants could well question whether the FOMC would allow the economy to "overheat," and they might see an incentive for the FOMC to renege. Although the FOMC can never bind future committees to a particular course of action, I think that incorporating a set of widely supported principles into the FOMC's strategy statement would ameliorate this problem. Let me conclude by saying that I consider this approach worthy of consideration by the FOMC and of more general public debate. 


\section{References}

Bernanke, Ben S. 2017. "Monetary Policy in a New Era." Paper prepared for conference on Rethinking Macroeconomic Policy, Peterson Institute for International Economics, Washington, October 12-13.

Kiley, Michael T., and John M. Roberts. 2017. "Monetary Policy in a Low Interest Rate World." Brookings Papers on Economic Activity, Spring, 317-72.

Laubach, Thomas, and John C. Williams. 2003. "Measuring the Natural Rate of Interest." Review of Economics and Statistics 85, no. 4: 1063-70.

Reifschneider, David, and John C. Williams. 2000. "Three Lessons for Monetary Policy in a Low-Inflation Era." Journal of Money, Credit and Banking 32, no. 4, pt. 2: 936-66. 